\title{
Mid-to-long-term Results of Hemi-resurfacing Arthroplasty and Metal-on-metal Hip Resurfacing Arthroplasty for Osteonecrosis of the Femoral Head
}

Masahiro Hasegawa ( $\square$ masahase@clin.medic.mie-u.ac.jp )

Mie University Graduate School of Medicine

Shine Tone

Mie University

Yohei Naito

Mie University

Hiroki Wakabayashi

Mie University

Akihiro Sudo

Mie University

Research article

Keywords: Osteonecrosis of the femoral head, Resurfacing, Hemi-resurfacing

Posted Date: July 20th, 2021

DOl: https://doi.org/10.21203/rs.3.rs-688518/v1

License: (c) (1) This work is licensed under a Creative Commons Attribution 4.0 International License. Read Full License 


\section{Abstract}

Background: Hemi-resurfacing arthroplasty (Hemi) and metal-on-metal hip resurfacing arthroplasty (HRA) are alternatives to conventional total hip arthroplasty (THA) for patients with osteonecrosis of the femoral head (ONFH). Mid- to long-term results were evaluated.

Methods: Twenty-three hips with osteonecrosis of the femoral head were treated, using Hemi in 12 and HRA in 11. Mean follow-up was 13.8 years in the Hemi group and 8.7 years in the HRA group. Mid- to long-term clinical scores, radiographic results, and survivorship were reviewed retrospectively.

Results: In the Hemi group, 8 hips were revised to THA due to migration. In the HRA group, 1 hip was revised due to adverse local tissue reaction. No evidence of any femoral loosening or neck narrowing was seen in either group. Clinical score was superior with HRA compared to Hemi. Ten-year survival rates were $64.2 \%$ and $90.9 \%$ in the Hemi and HRA groups, respectively. Survival rate in the Hemi group dropped to $22.0 \%$ at 14 years.

Conclusion: Hemi did not represent a better alternative to THA for patients with ONFH. HRA could offer attractive indications for 10 years.

\section{Background}

Osteonecrosis of the femoral head (ONFH) with collapse is problematic for orthopedic surgeons. Hemiresurfacing arthroplasty (Hemi) and metal-on-metal hip resurfacing arthroplasty (HRA) are alternatives to conventional total hip arthroplasty (THA) for patients with ONFH [1-3]. In a nationwide study from the United States, THA was clearly the most commonly performed (90\%), while HRA $(0.2 \%)$ and osteotomy (1\%) were performed markedly less frequently [4]. In a Japanese nationwide study, THA was performed in $79 \%$ of patients, with bipolar hemiarthroplasty (BP) in 17\%, HRA in 3\%, and Hemi in 1\% [5]. In Japan, patients who underwent osteotomy and bipolar hip arthroplasty for ONFH decreased, while those who underwent THA increased over time [6]. Hemi and HRA offer potential advantages of preserving bone, loading of the proximal femur, reduced risk of dislocation, and elimination of polyethylene debris that causes osteolysis compared with conventional THA $[3,7,8]$. In cases of femoral component failure, revision might be simpler compared with conventional THA and could not adversely affect the outcomes of THA $[8,9]$.

After achieving encouraging early results, findings of adverse local tissue reactions (ALTR) associated with metal wear debris and the recall of one design triggered a considerable reduction in the use of HRA worldwide [10,11]. Hemi has the advantages of avoiding an artificial bearing surface [12]. Hemi has been proposed as a reasonable alternative to THA. Beaule et al. [12] reported that overall survivorship rates were $79 \%, 59 \%$, and $45 \%$ at 5,10 , and 15 years, respectively.

Our aims were to report mid- to long-term outcomes of Hemi and HRA, and to compare results between Hemi and HRA. 


\section{Materials And Methods \\ Patients}

From 2004 to 2009, a total of 12 hips in 10 patients underwent Hemi for ONFH with Ficat stage III [13]. Between 2010 and 2014, 11 hips in 8 patients underwent HRA with Ficat stage III or IV [13]. Patients were resurfaced regardless of the size of the osteonecrotic lesion. The demographic characteristics of patients are shown in Table 1. Mean duration of follow-up was 13.8 years in the Hemi group and 8.7 years in the HRA group. The femoral prosthesis was a Cormet resurfacing head (Corin, Cirencester, UK) and the cup was a Cormet cup (Corin, Fig. 1). Both prostheses were made of cobalt-chromium alloy. The femoral prosthesis with short stem was cemented and the acetabular prosthesis was press-fitted (hybrid). Mean diameters of the resurfacing head were $46 \mathrm{~mm}$ (range, 42-52 $\mathrm{mm}$ ) and $48 \mathrm{~mm}$ (range, 44-52 $\mathrm{mm}$ ) in the Hemi and HRA groups, respectively. Mean cup diameter was $54 \mathrm{~mm}$ (range, 50-58 mm). Trochanteric flip osteotomy was performed to avoid compromising blood supply to the femoral head [14]. Size of the femoral prosthesis was determined intraoperatively using a ring template. The greater trochanter was fixed with a titanium alloy screw or poly L-lactic acid screw. Partial weight-bearing with the use of crutches was advised for the first 6 weeks after surgery.

\section{Evaluation}

Clinical results were analyzed using the Merle d'Aubigné and Postel scoring system [15]. Serial radiographs were obtained and analyzed by an independent observer $(\mathrm{MH})$. Component migration and loosening were evaluated. Radiographic loosening of the femoral component was defined by subsidence $\geq 5 \mathrm{~mm}$ [16]. Radiographic loosening of the acetabular component was defined as migration or radiolucency $>1 \mathrm{~mm}$ in all DeLee and Charnley zones $[17,18]$. Our institutional review board approved this study. Informed consent was obtained from all individual participants included in the study. Written informed consent to publish this information was obtained from study participants.

\section{Statistical analysis}

Differences between groups in demographic characteristics and clinical scores were compared using the Mann-Whitney U-test, Fisher's exact test, or Wilcoxon signed-rank test. Kaplan-Meier survivorship analysis was performed using revision for any reason as the end-point. Cox regression analysis was used to compare survival data. Data were statistically analyzed using $\mathrm{R}$ version 3.5.1 (R Foundation for Statistical Computing, Vienna, Austria; http://www.R-project.org/). Statistical significance was set at $p<$ 0.05 .

\section{Results}


Statistical significant differences were found in terms of sex, age, etiology, Ficat stage, and follow-up period (Table 1). In the Hemi group, mean Merle d'Aubigné and Postel score changed from 11.4 (range, 516) preoperatively to 13.5 (range, $11-18 ; p=0.0733$ ) at latest follow-up. Mean scores for pain, mobility and walking ability improved from 2.9 (range, 0-4), 3.2 (range, 1-6) and 5.3 (range, 4-6) preoperatively to 4.9 (range, 4-6), 3.7 (range, 2-6), and 4.9 (range, 4-6) at latest follow-up, respectively. In the HRA group, mean Merle d'Aubigné and Postel score improved significantly from 13.0 (range, 11-16) preoperatively to 16.2 (range, $6-18 ; p=0.0486$ ) at latest follow-up. Mean scores for pain, mobility and walking ability improved from 3.9 (range, 3-5), 3.8 (range, 3-5) and 5.3 (range, 4-6) preoperatively to 5.0 (range, 0-6), 5.3 (range, 2-6), and 5.8 (range, 4-6) at latest follow-up, respectively. Although preoperative score showed no difference between groups $(p=0.344)$, score at last follow-up was better in the HRA group than in the Hemi group $(p=0.009)$.

\section{Discussion}

Satisfactory outcomes were found in hips with HRA, but the survival rate was only $22 \%$ at 14 years after Hemi. Kobayashi et al. [5] reported a Japanese nationwide multicenter follow-up cohort study, and survival rates at 10 years were $95 \%$ in bipolar hemiarthroplasty, $94 \%$ in THA, $91 \%$ in HRA, and $72 \%$ in Hemi. These rates were comparable to those of the present study for HRA and Hemi. In this Japanese nationwide multicenter study, 11 of the $42 \mathrm{Hemi}$ required re-operation due to proximal migration (4 hips), unacceptable pain (4 hips), loosening (2 hips), and femoral neck fracture (1 hip). Compared with THA or bipolar hemiarthroplasty, Hemi showed a significantly higher risk of needing re-operation. Hemi has provided less than optimal pain relief in certain cases with acetabular involvement, leading some investigators to advise against the method [12]. In previous studies with HRA for ONFH, Beaulé et al [1] reported that the functional clinical outcomes of HRA are superior to those of Hemi with a mean followup of 4.9 years. Two of 56 hips with HRA were revised to THA due to femoral loosening, 4 of 28 hips with HRA were revised (1 sepsis and 3 for pain). Kabata et al. [19] showed that 5 of 16 hips underwent conversion to THA in Hemi with a mean follow-up of 5.5 years. In contrast, no HRA cases underwent revision surgery, with a mean follow-up of 6.5 years. Pain relief and implant survival in HRA were superior to those in Hemi without statistical analysis. The Australian NJR reported cumulative revision rates for HRA of $9.3 \%$ at 10 years and of $15.2 \%$ at 19 years. Rates for THA were $6.3 \%$ at 10 years and $12.2 \%$ at 19 years [20]. The Australian NJR reported significantly worse cumulative revision rates at 10 years for small femoral head sizes, with revision rates of $17.6 \%$ for femoral head sizes $<50 \mathrm{~mm}$, compared to $6.0 \%$ for femoral head sizes $\geq 50 \mathrm{~mm}[21]$.

One concern with resurfacing arthroplasty is the viability of the diminished femoral head. During the surgical procedure via posterolateral approach, the blood supply to the remaining part of the head might be damaged $[22,23]$. Damage to the blood supply during surgery could represent a potent risk factor for the femoral neck fracture after hip resurfacing [23]. We used trochanteric flip osteotomy to decrease damage to the blood supply. 
In 2008, Pandit et al. [10] reported that patients with HRA developed pseudotumor within 5 years. The cause might be a toxic reaction to an excess of particulate metal wear debris or a hypersensitivity reaction to metal debris. Many studies have confirmed such findings $[8,10,24]$. Women show a much higher incidence of pseudotumor than men. Many factors may contribute to this. Women are generally smaller than men, with higher head-neck ratios and a higher incidence of dysplasia, predisposing patients to high combined anteversion, all of which increase the risk. Furthermore, women are more likely to be hypersensitive to metals [8].

Hemi should not continue to be used because of worse long-term results. In contrast, HRA should not be discarded, except the recalled articular surface replacement (ASR) implant (DePuy, Warsaw, IN, USA). Implant survival rate was reported to be significantly higher for the non-ASR group than for the ASR group at 10 years [25]. Most reports of pseudotumor occurred before 10 years [10,26, 27], and no asymptomatic HRA with initially normal levels of metal ions and no pseudotumors developed new pseudotumor [28]. HRA could continue to be used in appropriate patients by appropriately trained surgeons. In young men who want to be very active, HRA remains an attractive option [8]. Limitations of this study included the small sample size and differences in demographics between the Hemi and HRA groups.

\section{Conclusion}

Hemi did not represent a better alternative to THA for patients with ONFH. HRA could be an attractive indication for 10 years. Follow-up studies for a longer period could reveal the utility of HRA for patients with ONFH.

\section{Abbreviations}

Hemi: Hemi-resurfacing arthroplasty; HRA: metal-on-metal hip resurfacing arthroplasty; THA: total hip arthroplasty; ONFH: osteonecrosis of the femoral head; ASR: articular surface replacement

\section{Declarations}

\section{Acknowledgements}

Authors have not received financial support for this work, and none of the authors have any conflicts of interest to declare in relation to this work.

\section{Authors' contributions}

$\mathrm{MH}$ was the main investigator and wrote the manuscript. ST, YN, and $\mathrm{WH}$ helped with data analysis. AS helped with the interpretation of the data and results. 


\section{Funding}

Not applicable.

\section{Availability of data and materials}

All data related to this case report are contained within the manuscript.

\section{Ethical approval and consent to participate}

This study was approved by the ethics committee of Mie University (H2018-083), and all participants provided written informed consent.

\section{Consent for publication}

Not applicable.

\section{Competing interests}

The authors declare that they have no competing interests.

\section{References}

1. Beaulé PE, Amstutz HC, Le Duff M, Dorey F. Surface arthroplasty for osteonecrosis of the hip: hemiresurfacing versus metal-on-metal hybrid resurfacing. J Arthroplasty. 2004;19(8 Suppl 3):54-8. doi. 10.1016/j.arth.2004.09.007.

2. Cuckler JM, Moore KD, Estrada L. Outcome of hemiresurfacing in osteonecrosis of the femoral head. Clin Orthop Relat Res. 2004;429:146-50. doi. 10.1097/01.blo.0000150121.88033.50.

3. Amstutz HC, Le Duff MJ. (2016) Hip resurfacing for osteonecrosis: two- to 18-year results of the Conserve Plus design and technique. Bone Joint J 98-B(7):901-9. https://doi: 10.1302/0301620X.98B7.36676.

4. Sodhi N, Acuna A, Etcheson J, Mohamed N, Davila I, Ehiorobo JO, Jones LC, Delanois RE, Mont MA. (2020) Management of osteonecrosis of the femoral head. Bone Joint J 102-B(7_Supple_B):122-8. doi: 10.1302/0301-620X.102B7.BJJ-2019-1611.R1.

5. Kobayashi S, Kubo T, Iwamoto Y, Fukushima W, Sugano N. (2018) Nationwide multicenter follow-up cohort study of hip arthroplasties performed for osteonecrosis of the femoral head. Int Orthop 42(7):1661-8. https://doi: 10.1007/s00264-018-3980-1. 
6. Kaneko S, Takegami Y, Seki T, Fukushima W, Sakai T, Ando W, Ishiguro N, Sugano N. (2020) Surgery trends for osteonecrosis of the femoral head: a fifteen-year multi-centre study in Japan. Int Orthop 44(4):761-9. https://doi: 10.1007/s00264-020-04480-6.

7. Ball ST, Le Duff MJ, Amstutz HC. Early results of conversion of a failed femoral component in hip resurfacing arthroplasty. J Bone Joint Surg Am. 2007;89(4):735-41. doi. 10.2106/JBJS.F.00708.

8. Murray DW, Grammatopoulos G, Gundle R, Gibbons CL, Whitwell D, Taylor A, Glyn-Jones S, Pandit HG, Ostlere S, Gill HS, Athanasou N, McLardy-Smith P. Hip resurfacing and pseudotumour. Hip Int. 2011;21(3):279-83. doi. 10.5301/HIP.2011.8405.

9. Kim SJ, Kang DG, Park SB, Kim JH. (2015) Is Hemiresurfacing Arthroplasty for Osteonecrosis of the Hip a Viable Solution? J Arthroplasty 30(6):987-92. https://doi: 10.1016/j.arth.2015.01.018.

10. Pandit H, Glyn-Jones S, McLardy-Smith P, Gundle R, Whitwell D, Gibbons CL, Ostlere S, Athanasou N, Gill HS, Murray DW. Pseudotumours associated with metal-on-metal hip resurfacings. J Bone Joint Surg Br. 2008;90(7):847-51. doi. 10.1302/0301-620X.90B7.20213.

11. Amstutz HC, Le Duff MJ. (2018) The mean ten-year results of metal-on-metal hybrid hip resurfacing arthroplasty. Bone Joint J 100-B(11):1424-33. doi: 10.1302/0301-620X.100B11.BJJ-2017-1459.R2.

12. Beaulé PE, Schmalzried TP, Campbell P, Dorey F, Amstutz HC. Duration of symptoms and outcome of hemiresurfacing for hip osteonecrosis. Clin Orthop Relat Res. 2001;385:104-17. doi. 10.1097/00003086-200104000-00018.

13. Ficat RP. Idiopathic bone necrosis of the femoral head. Early diagnosis and treatment. J Bone Joint Surg Br Jan. 1985;67(1):3-9. doi:10.1302/0301-620X.67B1.3155745.

14. Ganz R, Gill TJ, Gautier E, Ganz K, Krügel N, Berlemann U. Surgical dislocation of the adult hip a technique with full access to the femoral head and acetabulum without the risk of avascular necrosis. J Bone Joint Surg Br. 2001;83(8):1119-24. doi. 10.1302/0301-620x.83b8.11964.

15. d'Aubigné RM, Postel M. Functional results of hip arthroplasty with acrylic prosthesis. J Bone Joint Surg Am. 1954;36-A(3):451-75.

16. Ramakrishnan R, Jaffe WL, Kennedy WR. Metal-on-metal hip resurfacing radiographic evaluation techniques. J Arthroplasty. 2008;23(8):1099-104. doi:10.1016/j.arth.2007.09.021. https.

17. DeLee JG, Charnley J. Radiological demarcation of cemented sockets in total hip replacement. Clin Orthop Relat Res. 1976;121:20-32.

18. Hodgkinson JP, Shelley P, Wroblewski BM. The correlation between the roentgenographic appearance and operative findings at the bone-cement junction of the socket in Charnley low friction arthroplasties. Clin Orthop Relat Res. 1988;228:105-9.

19. Kabata T, Maeda T, Tanaka K, Yoshida H, Kajino Y, Horii T, Yagishita S, Tsuchiya H. (2011) Hemiresurfacing versus total resurfacing for osteonecrosis of the femoral head. J Orthop Surg (Hong Kong) 19(2):177-80. https://doi:10.1177/230949901101900209.

20. Australian Orthopaedic Association National Joint Replacement Registry (AOANJRR). Hip, Knee \& Shoulder Arthroplasty: 2020 Annual Report, Adelaide; AOA. 2020: 1-474. [Accessed from: https://aoanjrr.sahmri.com/annual-reports-2020]. 
21. Clough EJ, Clough TM. Metal on metal hip resurfacing arthroplasty: Where are we now? J Orthop. 2020;23:123-7. doi. 10.1016/j.jor.2020.12.036.

22. Khan A, Yates P, Lovering A, Bannister GC, Spencer RF. The effect of surgical approach on blood flow to the femoral head during resurfacing. J Bone Joint Surg Br. 2007;89(1):21-5. doi. 10.1302/0301620X.89B1.18330.

23. Steffen RT, Athanasou NA, Gill HS, Murray DW. Avascular necrosis associated with fracture of the femoral neck after hip resurfacing: histological assessment of femoral bone from retrieval specimens. J Bone Joint Surg Br. 2010;92(6):787-93. doi. 10.1302/0301-620X.92B6.23377.

24. Liow MHL, Kwon YM. (2017) Metal-on-metal total hip arthroplasty: risk factors for pseudotumours and clinical systematic evaluation. Int Orthop 41(5):885-92. https://doi: 10.1007/s00264-016-33051.

25. Park CW, Lim SJ, Kim JH, Park YS. Hip resurfacing arthroplasty for osteonecrosis of the femoral head: Implant-specific outcomes and risk factors for failure. J Orthop Translat. 2020;21:41-8. doi. 10.1016/j.jot.2019.12.005.

26. Hasegawa M, Yoshida K, Wakabayashi $\mathrm{H}$, Sudo A. Prevalence of adverse reactions to metal debris following metal-on-metal THA. Orthopedics. 2013;36(5):e606-12. doi. 10.3928/0147744720130426-23.

27. Matharu GS, Pandit HG, Murray DW. (2017) Poor Survivorship and Frequent Complications at a Median of 10 Years After Metal-on-Metal Hip Resurfacing Revision. Clin Orthop Relat Res 475(2):304-14. https://doi: 10.1007/s11999-016-4882-4.

28. Low AK, Matharu GS, Ostlere SJ, Murray DW, Pandit HG. (2016) How Should We Follow-Up Asymptomatic Metal-on-Metal Hip Resurfacing Patients? A Prospective Longitudinal Cohort Study. J Arthroplasty 31(1):146-51. https://doi:10.1016/j.arth.2015.08.007.

\section{Table}

Due to technical limitations, table 1 is only available as a download in the Supplemental Files section.

\section{Figures}




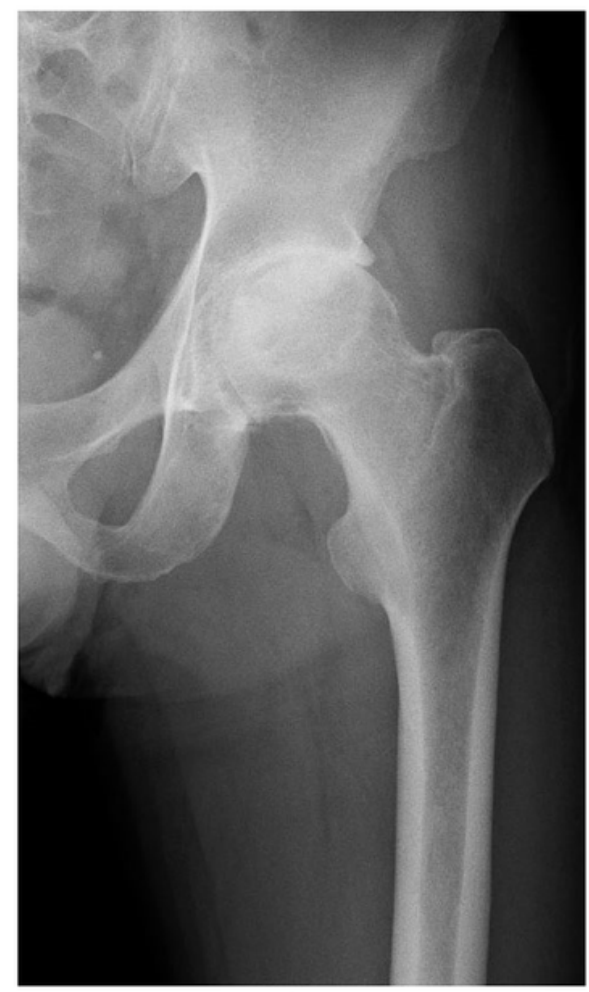

A

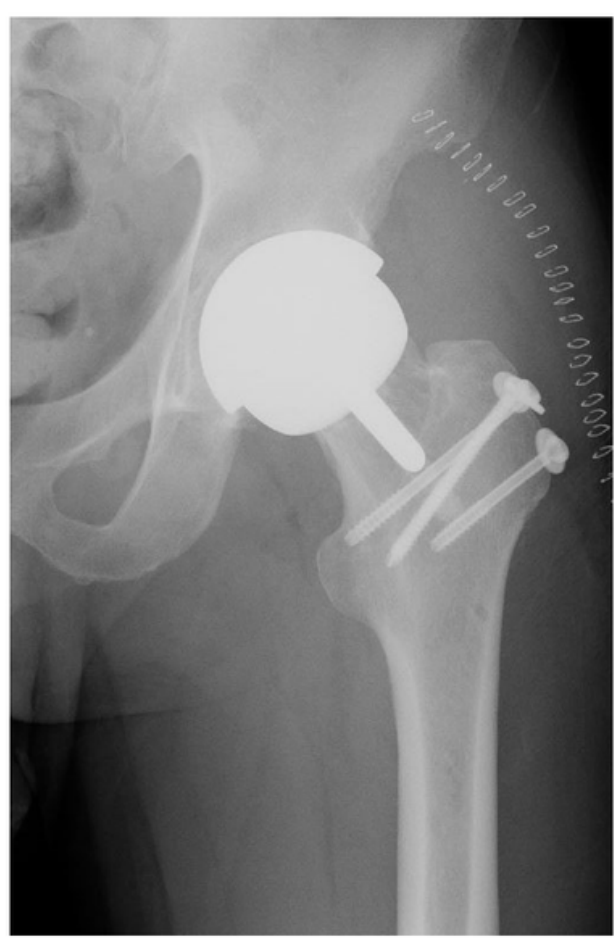

B

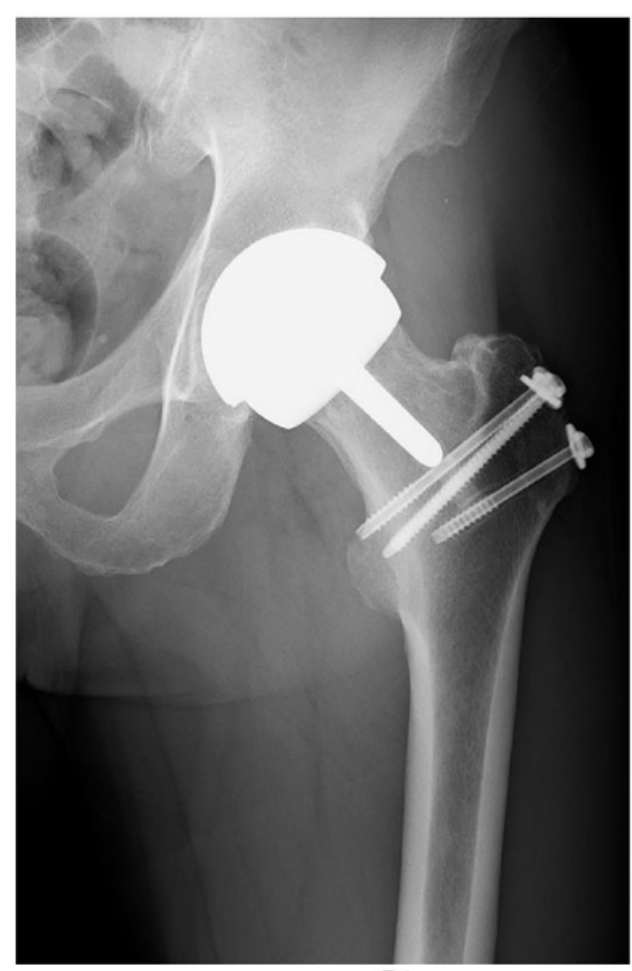

$\mathbf{C}$

\section{Figure 1}

Representative case of metal-on-metal hip resurfacing arthroplasty. A) Preoperative radiograph of a 49year-old man with Ficat stage IV osteonecrosis of the femoral head. B) Radiograph immediately after surgery. C) Radiograph after 8 years shows no loosening.

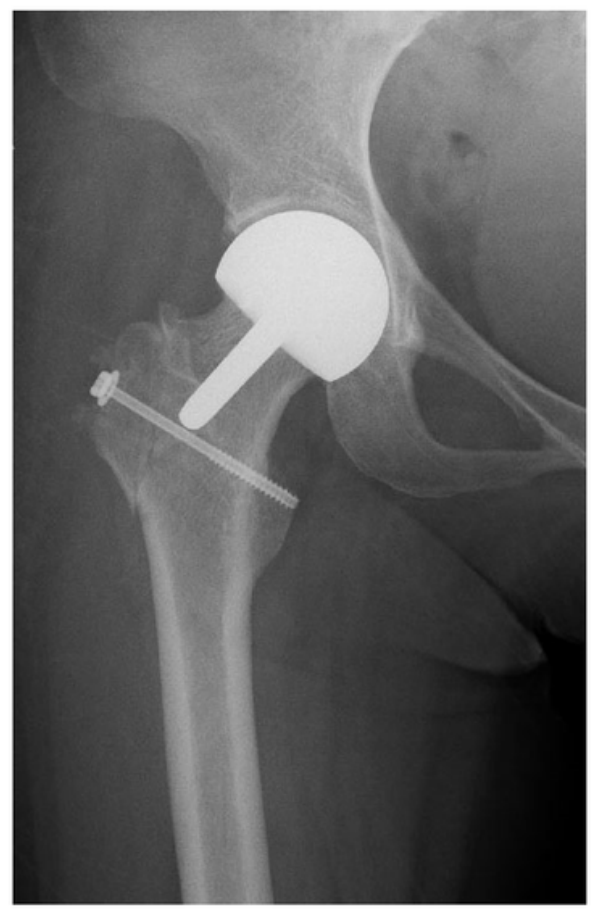

A

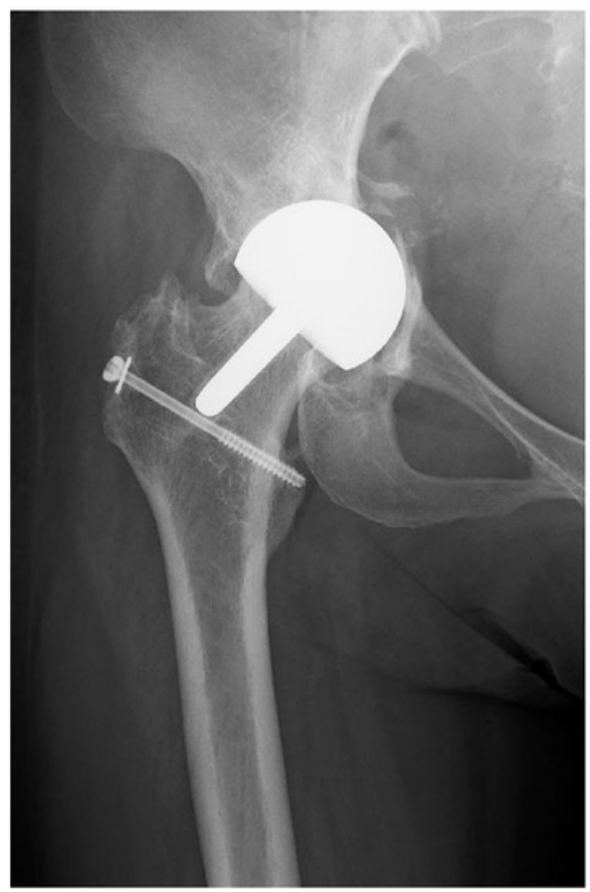

B

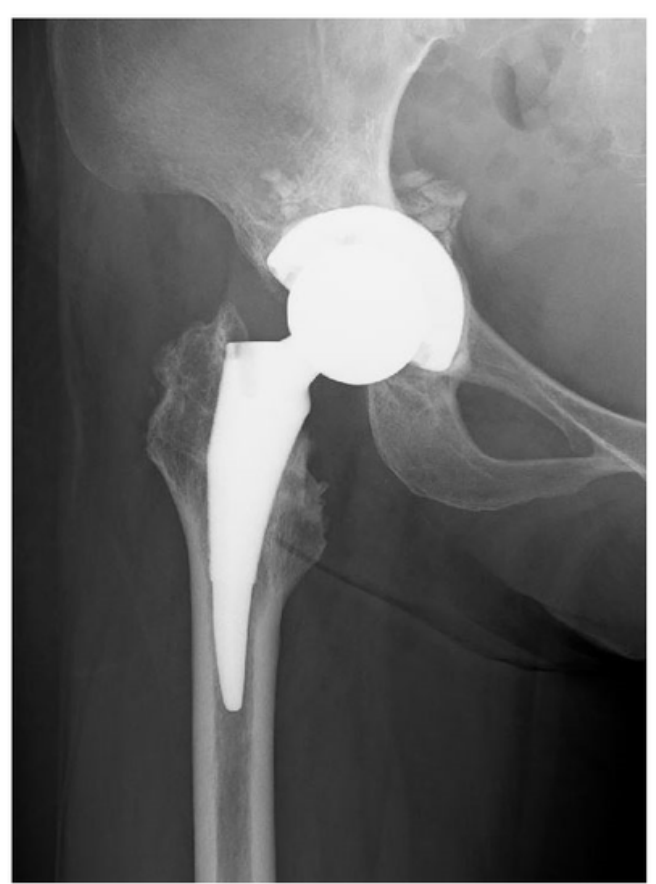

C 


\section{Figure 2}

Case of migration after hemiarthroplasty. A) Radiograph immediately after hemi-resurfacing arthroplasty of a 38-year-old woman with Ficat stage III of osteonecrosis of the femoral head. (B) Radiograph after 11 years shows severe migration. (C) Radiograph after conversion to total hip arthroplasty.

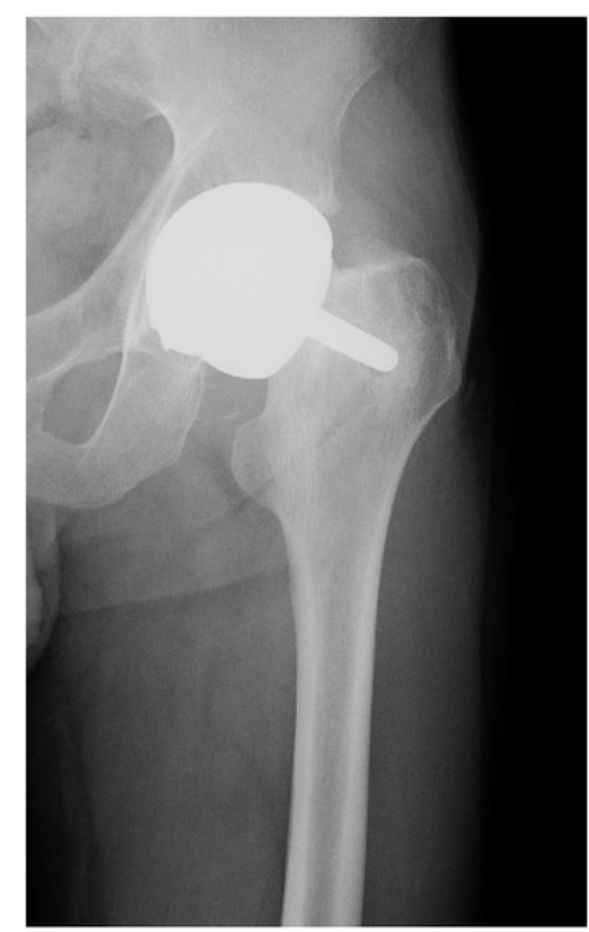

A

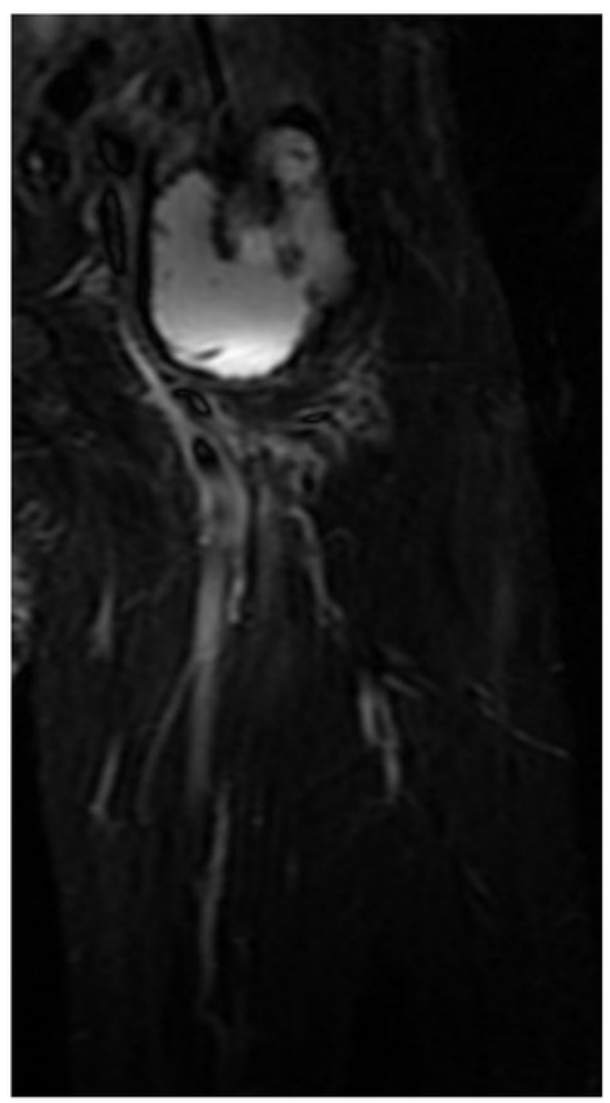

B
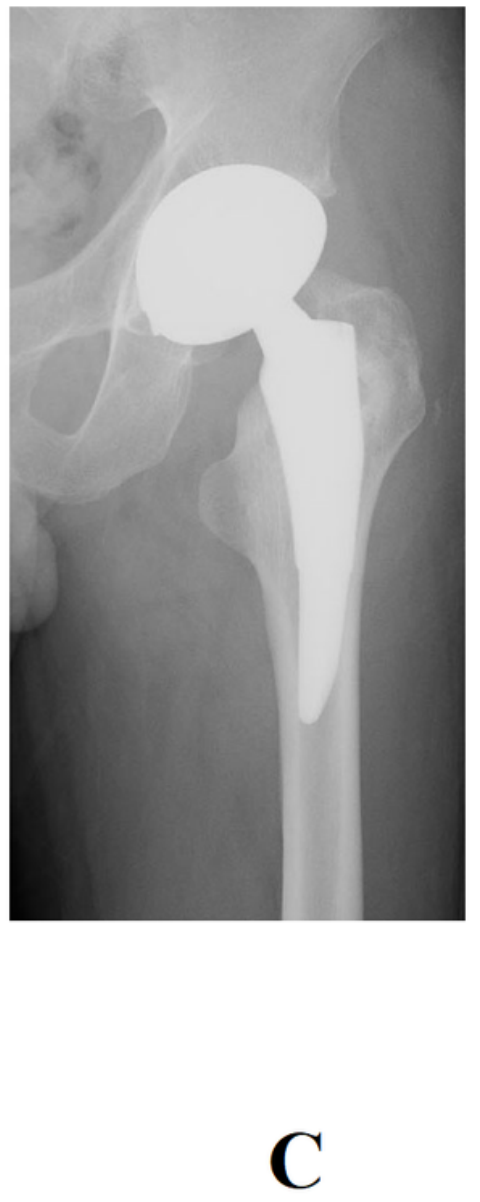

\section{Figure 3}

Case of adverse local tissue reaction after metal-on-metal hip resurfacing arthroplasty. (A) Radiograph after 2.5 years of a 44-year-old man with Ficat stage III of osteonecrosis of the femoral head shows loosening of femoral component. (B) Magnetic resonance imaging shows pseudotumor. (C) Radiograph after conversion to total hip arthroplasty. 


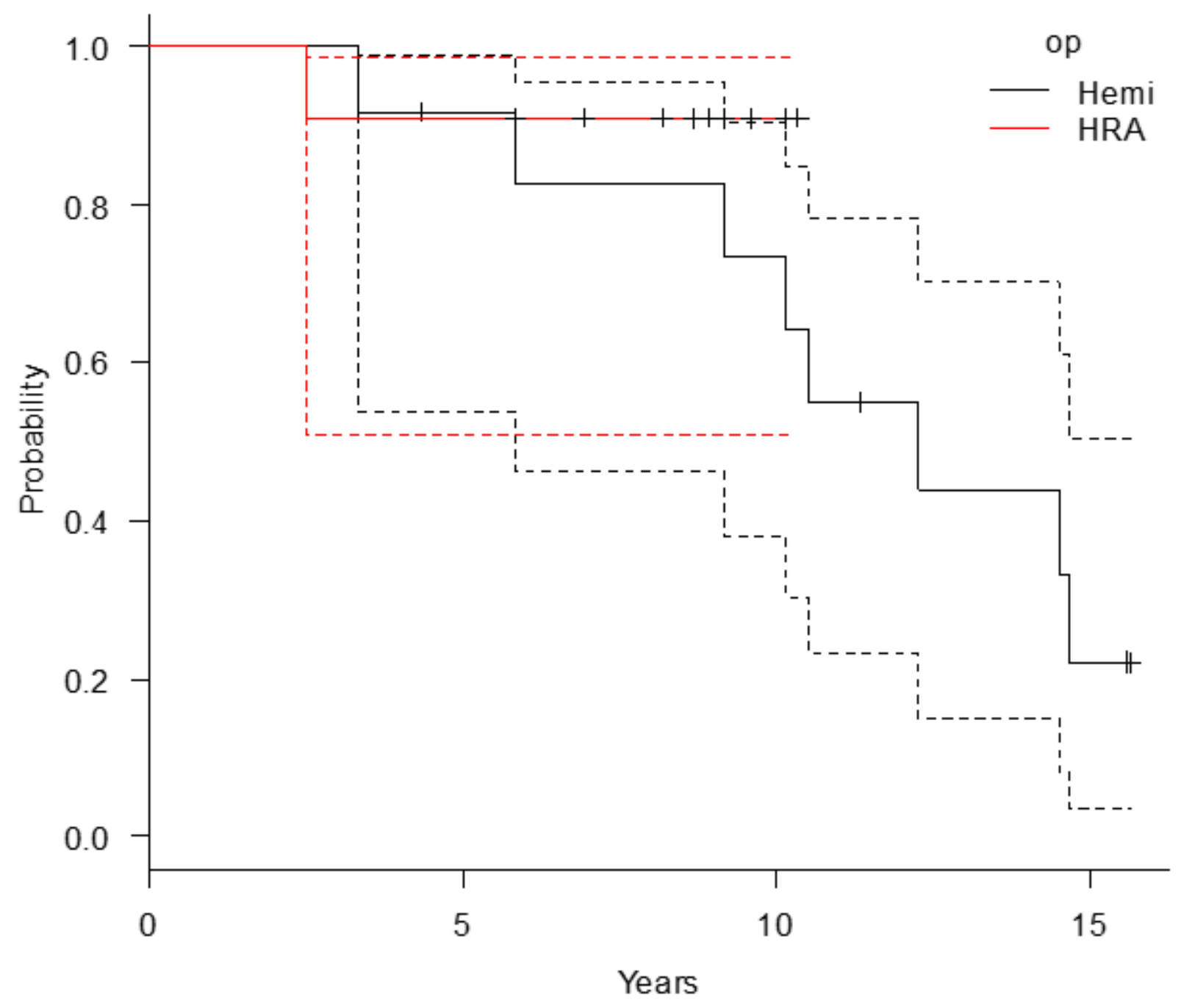

Figure 4

Kaplan-Meier survival curves depict $64.2 \%$ and $90.9 \%$ revision-free survivorship at 10 years in the Hemi and HRA groups, respectively. The rate in Hemi group depicts $22.0 \%$ at 14 years. Hemi: hemi-resurfacing arthroplasty, HRA: metal-on-metal hip resurfacing arthroplasty.

\section{Supplementary Files}

This is a list of supplementary files associated with this preprint. Click to download.

- Table1Demogra2nc.xisx 